\title{
METHANOL POISONING;
}

CHALLENGING DIAGNOSIS AND MANAGEMENT WITHOUT FOMEPIZOLE AND ETHANOL.

1. Assistant Professor and Head of Department of Nephrology, Lahore General Hospital.

2. Postgraduate Resident of Medicine 3. Previous Professor of Nephrology

Correspondence Address:

Dr. Aurangzeb Afzal

Assistant Professor and

Head of Department of Nephrology,

Lahore General Hospital.

aurangzebafzal@gmail.com

Article received on: 01/12/2016

Accepted for publication: 05/02/2017

Received after proof reading: 07/03/2017

\section{Dr. Aurangzeb Afzal', Dr. Sana Fatima², Dr. Aizaz Mand Ahmed}

ABSTRACT: Acute methanol poisoning produces severe metabolic acidosis, increased anion and osmolal gaps. These metabolic disturbances are due to accumulation of formic acid with has serious neurological sequelae. If renal functions starts deteriorating that is associated with increased mortality. Early diagnosis and treatment can reduce morbidity and mortality. Treatment include infusion of sodium bicarbonate and administration of ethanol orally or parentally to inhibit the production of formic acid from methanol. Hemodialysis is helpful in removal of methanol and its breakdown products from circulation and also in correcting acidosis. We report the case of a boy admitted to the emergency room with a history of acute illness, characterized by nausea, vomiting, blurred vision, and shortness of breath. Arterial blood gases showed severe metabolic acidosis with high anion gap. He had ingested large quantity of alcohol containing methanol. The patient was managed with hemodialysis and strong intravenous hydration. He improved well and made a full recovery.

Key words: Methanol poisoning, Metabolic acidosis,

Article Citation: Afzal A, Fatima S, Ahmed AM. Methanol poisoning; challenging diagnosis and management without fomepizole and ethanol. Professional Med J 2017;24(3):490-494. DOI: 10.17957/TPMJ/17.3751

\section{BACKGROUND}

Methanol poisoning is rarely described in the literature; some cases are reported as accidental ingestion and few cases are reported as deliberate use. For this reason, we report here a case of methanol poisoning which was unusual in its presentation, discussing clinical and laboratory manifestations, management, and evolution. Methanol poisoning should be suspected in any patient presenting with epigastric pain, blurred vision and laboratory results indicating metabolic acidosis with increased anion and osmolal gaps irrespective of renal function tests. Early diagnosis and treatment can reduce the morbidity and mortality.

\section{CASE PRESENTATION}

A 20 year old unmarried gentleman, shopkeeper by profession presented with complains of recurrent vomiting and Progressive drowsiness for 36 hours and Blurring of vision, shortness of breath for 12 hours.

$\mathrm{He}$ ingested 1 Littre of non-branded locally manufactured alcohol 36 hours ago after which he had 2 episodes of vomiting, vomiting free period of 24 hours, followed by 9 episodes. At the same time he complained of progressive drowsiness but no h/o irritability, aggressive behavior, headache, fits, blurring of vision at that time. After further 24 hours he developed complain of worsening shortness of but no h/o productive cough, heamoptysis, sweating, palpitations and chest pain. Progressively worsening blurring of vision with no h/o orbital pain, watering, itching or trauma.

\section{EXAMINATION}

Patient was lying in bed not fully oriented in time place and person with following vitals: Pulse $112 /$ min (regular), blood pressure 130/80 mm of $\mathrm{Hg}$, temperature $98.6 \mathrm{~F}$, and respiratory rate $30 /$ minute. General physical examination was unremarkable.

Systemic examination revealed Glasgow coma scale $=12 / 15$, pupils mid dilated and sluggishly reactive to light, later on patient developed bilateral afferent pupillary defect (APD). Figure-1. 


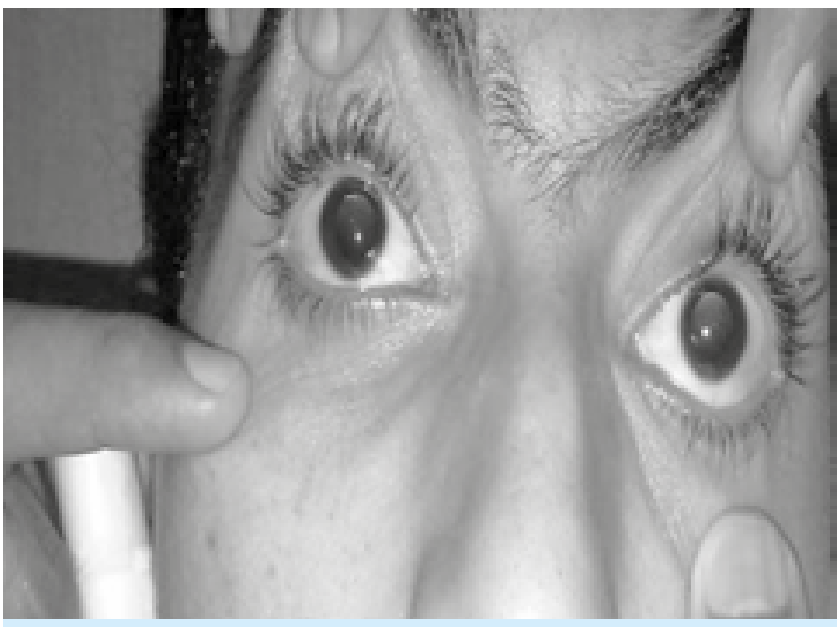

Figure-1. Dilated pupils with $b / l$ afferent pupillary defect

In motor system, he moving all limbs, reflexes normal, plantars down going. Sings of meningeal irritation were negative. Fundoscpy showed disc edema with erythema, heamorrhage at 11'o clock position on right side. He just appreciated hand movements. Rest systemic examination was unremarkable.

\section{INVESTIGATIONS}

CBC normal, RFT's normal, LFT'S normal, BSL normal, Serum amylase and lipase normal.

URINE ROUTINE: PH 5.0, proteins ++ , glucose nil, blood ++ , WBC 2, oxalates absent (post Urinary bladder catheterization), urinary ketones negative.

ABGs: $\mathrm{PH} 7.13, \mathrm{PCO} 2=6.7, \mathrm{PO} 2=82.2$, Sat $\mathrm{O} 2=$ $93 \%, \mathrm{HCO}=2.2$, sodium $=133$, chloride $=75$, Anion gap $=55.8$, Serum osmolality: calculated $=$ 284, measured 304= osmolal gap 20 .

Electrocardiography (ECG), Ultrasound abdomen, Chest x-ray (PA view) normal. Alcohol screen was done only by a private sector lab with special request serum methanol level was $9 \mathrm{mg} / \mathrm{dl}$, ethanol and ethylene glycol levels were negative.

We therefore assumed the possibility of Methanol intoxication, Ethylene glycol intoxication, Lactic acidosis and started managing patient with I/V fluids, I/V NaHCO3( total $450 \mathrm{ml}$ was given), Tab folic acid $5 \mathrm{mg}$ through N/G QID, Inj. Thiamine $10 \mathrm{mg} \mathrm{I} / \mathrm{V}$ stat then I/V OD, Tab pyridoxine $50 \mathrm{mg}$ through N/G BD, Inj. Omeprazole 40mg I/V OD, Inj. Metoclopramide I/N TID, Inj. Ceftriaxone $1 \mathrm{~g} \mathrm{I/V}$ BID, Inj. Metronidazole 500 mg I/V TID.

Patient underwent a session of haemodialysis for 4 hours through a double lumen catheter placed in right internal jugular vein.

The patient improved progressively after hemodialysis with correction of his metabolic acidosis. Biochemical profile of patient remained stable throughout the hospital stay. (Table-I and II)

\begin{tabular}{|l|c|c|c|}
\hline & $\begin{array}{c}\text { At } \\
\text { presentation }\end{array}$ & $\begin{array}{c}\text { After } \mathrm{HCO}_{3} \\
\text { replacement }\end{array}$ & $\begin{array}{c}\text { After } \\
\text { dialysis }\end{array}$ \\
\hline $\mathrm{PH}$ & 7.13 & 7.2 & 7.39 \\
\hline $\mathrm{PCO}_{2}$ & 6.7 & 18.2 & 41 \\
\hline $\mathrm{PO}_{2}$ & 82.2 & 88 & 88 \\
\hline $\mathrm{HCO}_{3}$ & 2.2 & 11.7 & 23 \\
\hline $\mathrm{ANION}^{2} \mathrm{GAP}$ & 55.8 & 46.3 & 12 \\
\hline \multicolumn{2}{|c|}{ Table-I. Evolution of acid base balance } \\
\hline
\end{tabular}

\begin{tabular}{|l|c|c|c|}
\hline & Day 1 & Day 3 & Day 5 \\
\hline UREA mg/dl & 25 & 28 & 30 \\
\hline CREATININE mg/dl & 0.6 & 0.5 & 0.8 \\
\hline ALBUMIN g/l & 4.4 & 4.0 & 3.9 \\
\hline GLUCOSE mg/dl & 123 & 108 & 117 \\
\hline AST & 35 & 40 & 38 \\
\hline ALT & 30 & 38 & 28 \\
\hline LDH & 288 & 250 & 221 \\
\hline \multicolumn{3}{|c|}{ Table-Il. Trend of laboratory findings } \\
\hline
\end{tabular}

Opthalmology department prescribed lutein 10 $\mathrm{mg} /$ day as even after dialysis patient was having limited colour vision. He was given lutein therapy for 6 months during which patients colour vision gradually turned to normal.

MRI brain with contrast was done on next day of dialysis and showed subcortical white matter and basal ganglia hyper-intensity and low-signalintensity bilateral putaminal foci. 


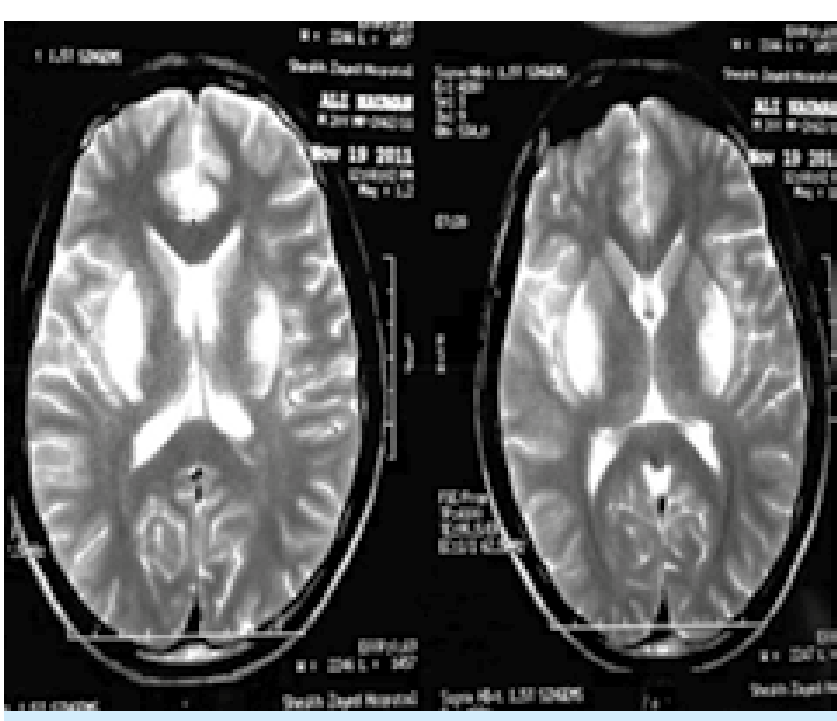

Figure-2. MRI Brain with contrast

Patient was followed for 18 months during which his examination and investigations were unremarkable.

\section{DISCUSSION}

Methanol is a chemical with the formula $\mathrm{CH} 3 \mathrm{OH}$ (often abbreviated $\mathrm{MeOH}$ ) and is very toxic to the humans. Methanol acquired the name "wood alcohol" because it was once produced chiefly as a byproduct of the destructive distillation of wood. Today, industrial methanol is produced in a catalytic process directly from carbon monoxide, carbon dioxide, and hydrogen. The pathways for poisoning are inhalation, cutaneous, and digestive tract, in most cases by swallowing. Methanol poisoning in children is rare and there are only isolated reports of homicidal poisoning and seizures. ${ }^{1,2}$

Methanol is the simplest alcohol being only a methyl group linked to a hydroxyl group. It is a light, volatile, colorless, flamable liquid with a distinctive odor very similar to that of ethanol (drinking alcohol). ${ }^{3}$ However, unlike ethanol, methanol is highly toxic and unfit for consumption. At room temperature, it is a polar liquid, and is used as an antifreeze, solvent, fuel, and as a denaturant for ethanol. It is also used for producing biodiesel via trans esterification reaction. Clinical features are inebriation progressing to coma, seizures and extra-pyramidal features, confusion, agitation, stupor, fits, faints, coma, , blurring of vision, disc edema, retinal sheen, Optic neuritis, Ischemia or hemorrhage in basal ganglia especially putamen ${ }^{5}$, nausea, vomiting, abdominal pain, pancreatitis, hypotention progressing to shock, tachypnea. The clinical manifestations of methanol poisoning are well summarized by the stages of intoxication which are described as follows.

In the first phase, there is minimal decrease in central nervous system activity, weakness, dizziness, and nausea.

The second phase is marked by the development of metabolic acidosis characterized by vomiting, abdominal pain, confusion, visual disturbances, photophobia, blurred vision, bilateral mydriasis, unresponsiveness to light, and occasional blindness.

In the third phase, in direct relation to the degree of metabolic acidosis, neuronal injury occurs with retinal necrosis and hemorrhage in the basal ganglia of the brain. At this stage there is hypotension, coma, and Kussmaul breathing. Our patient was considered to be in the third phase of methanol toxicity.

Diagnosis of methanol poisoning is based on the suspicion of ingestion, the presence of visual disturbances, the onset of metabolic acidosis with elevated anion and osmolal gaps, and markedly increased liver enzymes.

Confirmation is by determining the plasma levels of methanol. The toxic methanol dose is $10-30 \mathrm{~mL}$ $(100 \mathrm{mg} / \mathrm{kg})$, although lower intakes have caused blindness. It is lethal above $60-240 \mathrm{~mL}(340 \mathrm{mg} /$ $\mathrm{kg}$ ). A dose of $30 \mathrm{~mL}$ of $100 \%$ methanol can be considered fatal.

Concentrations above $0.2 \mathrm{~g} / \mathrm{L}$ are toxic, values higher than $0.5 \mathrm{~g} / \mathrm{L}$ indicate severe poisoning, and concentrations above $0.9 \mathrm{~g} / \mathrm{L}$ are potentially deadly. Serum formate levels have been shown to correlate better with the clinical findings compared to methanol levels. If ingested, as little 
as $10 \mathrm{ml}$ of pure methanol can cause permanent blindness by destruction of optic nerve; $30 \mathrm{ml}$ is potentially fatal, although the median lethal dose is typically $100 \mathrm{ml}\left(1-2 \mathrm{ml} / \mathrm{kg}\right.$ of pure methanol). ${ }^{6}$

Methanol is rapidly absorbed from the gastrointestinal tract, giving peak plasma levels after 30-90 minutes. The serum half-life ranges from 14 to 30 hours and is distributed freely. . Metabolism is hepatic. Excretion is Pulmonary/ renal. The kidney, in untreated patients, removes less than $5 \%$.

Treatment consists of gastric lavage, if the patient is conscious and presents in early stage, sodium bicarbonate is administered intravenously to combat severe acidosis. ${ }^{7}$ Various reports suggest that administration of sodium bicarbonate reduces morbidity and mortality. Ethanol administration either parentally or orally plays the main role in the treatment of methanol poisoning. ${ }^{5}$ It inhibits conversion of methanol to its toxic metabolites. $10 \%$ solution is given as a continuous infusion. In conscious patients, ethanol $0.6 \mathrm{gm} / \mathrm{kg}$ may be given orally. In developed countries fomepizole is used in methanol toxic ingestion and acts to inhibit the breakdown of this toxin into their active toxic metabolites. Fomepizole is a competitive inhibitor of the enzyme alcohol dehydrogenase ${ }^{8}$, found in the liver. By competitively inhibiting the first enzyme in the metabolism of methanol, fomepizole slows the production of the toxic metabolites. The slower rate of metabolite production allows the liver to process and excrete the metabolites as they are produced, limiting the accumulation in tissues such as the kidney and eye. As a result, much of the organ damage is avoided. Fomepizole is most effective when given soon after ingestion of ethylene glycol or methanol. Delaying its administration allows for the generation of harmful metabolites. ${ }^{9}$ In developing countries like Pakistan fomepizole is not used due to unavailability but our case has shown that even without using fomepizole and i.v ethanol, methanol intoxication can be treated.

Hemodialysis is another important technique to remove methanol and formate from circulation and should be used in all cases with ocular manifestation, renal impairment and/or peak methanol greater than $50 \mathrm{mg} / \mathrm{dl}$. Folate is an important cofactor in the oxidation of formate to carbon dioxide and water. Thus, it may play a role as a therapeutic adjunct in the treatment of methanol poisoning. ${ }^{10}$

Copyright (C) 05 Feb, 2017.

\section{REFERENCES}

1. J. M. Beno, R. Hartman, C. Wallace, D. Nemeth, and S. LaPoint, "Homicidal methanol poisoning in a child," Journal of Analytical Toxicology, vol. 35, no. 7, pp. 524-528, 2011. View at Google Scholar · View at Scopus.

2. J. C. van Gaal, R. Petru, and L. T. J. Sie, "An infant with unexplained epilepsy," Nederlands Tijdschrift voor Geneeskunde, vol. 154, Article ID A2420, 2010.

3. National Institute for Occupational Safety and Health (22 August 2008). "The Emergency Response Safety and Health Database: Methanol”. Retrieved 17 March 2009.

4. Prabhakaran V, Ettler H, Mills A. Methanol poisoning: two cases with similar plasma methanol concentrations but different outcome. Can Med Assoc J 1993; 148(6) 981-84.

5. Burhart KK, Kulig KW. The other alcohols. Methanol, ethylene glycol and isopropanol. Emerg Med Clin North Am 1990; 8:913-28.

6. Vale A. Methanol. Medicine. 2007; 35: 633-634.

7. Satar S, Alpay NR, Sebe A, Gokel Y. Emergency hemodialysis in the management of intoxication. Am J Ther. 2006 Sep-Oct; 13(5):404-10.

8. Casavant MJ (January 2001). "Fomepizole in the treatment of poisoning".

9. "Fomepizole for Ethylene Glycol and Methanol Poisoning".

10. Kruse JA. Methanol poisoning. Intensive Care Med. 1992; 18(7):391-7. 


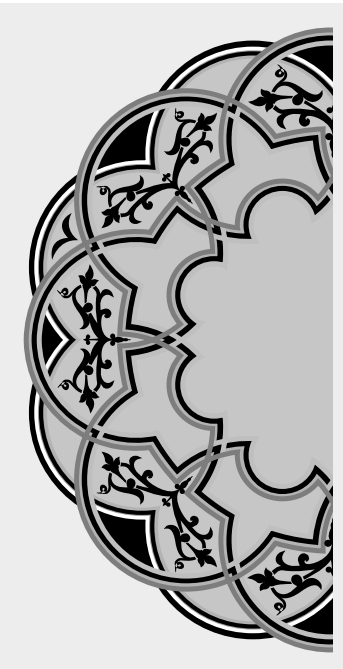

\title{
"By learning you will teach; by teaching you will learn."
}

\author{
Latin Proverb
}

\section{AUTHORSHIP AND CONTRIBUTION DECLARATION}

\begin{tabular}{|c|l|l|l|}
\hline Sr. \# & \multicolumn{1}{|c|}{ Author-s Full Name } & \multicolumn{1}{|c|}{ Contribution to the paper } & $\begin{array}{c}\text { Author=s } \\
\text { Signature }\end{array}$ \\
\hline 1 & Dr. Aurangzeb Afzal & 1st Author \\
\hline 2 & Dr. Sana Fatima & 2nd Author \\
\hline 3 & Dr. Aizaz Mand Ahmed & 3rd Author & \\
\hline
\end{tabular}

